ORIGINAL ARTICLE

\title{
An evaluation of differences in hip external rotation strength and range of motion between female dancers and non- dancers
}

\author{
A Gupta, B Fernihough, G Bailey, P Bombeck, A Clarke, D Hopper
}

Br J Sports Med 2004;38:778-783. doi: 10.1136/bjsm.2003.010827

See end of article for authors' affiliations

Correspondence to: Dr Hopper, School of Physiotherapy, Curtin University, Bentley, WA 6102, Australia; d.hopper@curtin.edu.au

Accepted 6 January 2004

\begin{abstract}
Objectives: To evaluate the differences in hip external rotation (ER) strength and inner, outer, and total hip ER range of motion (ROM) between dancers and non-dancers and between left and right sides in each group.

Methods: Seventy one subjects (34 dancers and 37 non-dancers) volunteered for this study. The strength (truncated range average torque (TRAT), work, and angle specific torque (AST)) of the hip external rotator muscle group, through the full available active hip ER ROM, was evaluated using concentric isokinetic $(30 \%$ s) testing on a KinCom dynamometer. Adjustment for lean body mass (LBM) was made for comparison of strength between groups. A two way repeated analysis of covariance was used to compare strength between groups. A two way repeated analysis of variance was used to compare strength between sides and ROM between groups and sides. Bonferroni correction was made for multiple analyses, and significance was accepted at $\mathrm{p} \leqslant 0.05$.

Results: AST at $0^{\circ}, 20^{\circ}, 30^{\circ}$, and $40^{\circ}$ of hip ER was greater in the dancers than the non-dancers $(p \leqslant 0.022)$. TRAT, work, $\mathrm{AST}_{0}{ }^{\circ}, \mathrm{AST}_{20}$, and $\mathrm{AST}_{30^{\circ}}$ of hip $\mathrm{ER}$ were all greater on the right side than the left ( $p=0.007)$ in both groups. Dancers had greater inner ER ROM ( $p=0.013)$ and less outer ER ROM than non-dancers $(p \leqslant 0.001)$. There was no difference in total ER ROM between groups $(p=0.133)$. The right side had greater inner ER $(p \leqslant 0.001)$ and total ER ROM $(p \leqslant 0.001)$ than the left in both groups. Conclusions: Ballet dancers have greater inner range, angle specific strength and inner range ER ROM, demonstrated by a shift in the dancers' strength curves. This shift in the strength curve towards the inner range of hip ER may be an adaptive training response.
\end{abstract}

B allet is synonymous with creating effortless movement at the extremes of motion by the human body. Central to it is attaining maximal hip external rotation (ER) to turn the feet and legs out from the hip joint to a $90^{\circ}$ position..$^{1}$ The five positions of ballet require this turnout position to be achieved through the hip, avoiding compensations at joints above or below the hip..$^{2-7}$ The hip muscles are critical in dancers, as they stabilise the pelvis for balance and generate force while controlling the lower limb during the wide range of dance manoeuvres. ${ }^{589}$

The emphasis placed on achieving extreme hip ER results in alterations in dancers' biomechanics, as this is an "abnormal" joint position and may lead to tissue injury in the kinetic chain. ${ }^{510-12}$ Epidemiological studies confirm the high incidence of injury in dancers, ranging from $42 \%$ to $85 \%$, with most occurring at the lower extremity. ${ }^{23-15}$ Hip muscle strength has been implicated in lower extremity injury in athletic populations. ${ }^{16} 17$

Specific training effects for velocity, ${ }^{18}$ muscle action, and angle are well established in athletic populations, ${ }^{19}{ }^{20}$ but the angle specific strength of the hip external rotators has not been determined in dancers. Velocity specific gain in quadriceps strength measured at $180 \%$, and not at lower speeds of 45 and $90 \%$, was found in both female and male dancers over a four month period; the gains were made only at functional velocities. ${ }^{21}$ In support of functional strength gains, a study of novice female dancers showed a greater increase in isometric strength of hip flexor, abductor, adductor, and internal and external rotator muscle groups than in a well matched control group over 12 months. ${ }^{22}$ Furthermore, isokinetic peak torque measurement of concentric hip strength in dancers showed greater torque production by the external rotators than the internal rotators. $^{923}$ In non-dancers, internal rotator torques have been shown to be greater than the external rotator torques. ${ }^{24} 25$ These findings may indicate an adaptive response of the external rotators of ballet dancers to their functional demands.

Dancers are unique in their physical and physiological characteristics. ${ }^{26}$ As strength production is related to the amount of muscle able to generate force, it is essential to normalise for lean body mass (LBM) when comparing nondancers with dancers. ${ }^{27}$ The body fat of female ballet dancers has been shown to be $43 \%$ lower than that of age and weight matched non-dancers. ${ }^{28}$ It is essential that dancers have optimal muscle strength to achieve the required extreme hip ER joint position.

There is a paucity of research on differences in hip ER strength and range of motion (ROM) between sides, even though the position of extreme hip ER is vital to the dancer. Investigations of strength differences at the hip between sides have suggested that significant asymmetry is associated with an increased incidence of lower quadrant injury in female athletes. ${ }^{16} 1729$ Side to side differences in dancers' strength have not been investigated.

The purposes of this study were to:

- evaluate if hip ER strength is greater in female dancers than in non-dancers;

Abbreviations: AST, angle specific torquen; $E R$, external rotation; IR, internal rotation; LBM, lean body mass; ROM, range of motion; TRAT, truncated range average torque 
- evaluate if there is a difference in hip ER strength between sides in female dancers and non-dancers;

- evaluate if there is a difference in hip ER ROM between female dancers and non-dancers and between left and right sides.

\section{METHODS}

This investigation is a cross sectional, two factor, repeated measures design. The first independent variable (betweensubjects factor) was the group with two levels: dancers and non-dancers. The second independent variable (withinsubjects factor) was the side (repeated measure): left and right.

All dependent variables were measured on left and right sides. Hip external rotator strength was measured as: the truncated range average torque (TRAT; N.m), work (J), and angle specific torque (AST; N.m) at $0^{\circ}, 20^{\circ}, 30^{\circ}$, and $40^{\circ}$ of hip ER. The dependent variable measured to evaluate hip ER ROM was the truncated hip ER ROM, described as the total ER ROM, outer ER ROM (start ER to $0^{\circ}$ ), and inner ER ROM $\left(0^{\circ}\right.$ to end ER). The position of $0^{\circ}$ is the anatomical neutral position of the hip, where, in the prone position, the lower leg is vertical with knee flexed to $90^{\circ}$. LBM was the covariate used to compare strength between groups.

\section{Subjects}

Thirty four female dancers training in ballet and contemporary styles volunteered for this study. They were recruited from the West Australian Academy of Performing Arts. Thirty seven age and sex matched non-dancers volunteered from the student population at the Curtin University of Technology, Bentley Campus. Table 1 presents subject profiles.

Inclusion criteria were as follows.

- All subjects were healthy women aged 17-24 years.

- Dancers had trained for a minimum of three years (part or full time).

- Dancers participated for at least 22 hours/week of training for the six months before testing.

Exclusion criteria were as follows.

- Dancers were excluded if they had injury or pain that could be exacerbated by isokinetic testing.

- Dancers were excluded if they had injury or pain that could preclude them from dancing at the time of isokinetic testing.

- Non-dancers were excluded if they had a history of lower quadrant injury or pain.

Each subject was required to attend the KinCom laboratory at Curtin University of Technology on one occasion. An information sheet explaining the aims of the study and strength testing procedure was provided and an informed

\begin{tabular}{lll}
\hline \multicolumn{2}{l}{ Table 1} & \multicolumn{2}{l}{ Subject profiles } \\
\hline & Dancers $(\mathbf{n}=\mathbf{3 4})$ & Non-dancers $(\mathbf{n}=\mathbf{3 7})$ \\
\hline Age (years) & $19.1(1.4)$ & $19.8(1.6)$ \\
Mass $(\mathrm{kg})$ & $54.45(5.1)$ & $59.44(7.8)$ \\
Height $(\mathrm{m})$ & $1.65(0.05)$ & $1.67(0.06)$ \\
LBM $(\mathrm{kg})$ & $44.33(3.33)$ & $43.53(3.34)$ \\
Dance years* & $7.6(0.53)$ & 0 \\
\hline Values are mean (SD). & \\
*Years of dance training. & \\
LBM, Lean body mass. & \\
\hline
\end{tabular}

consent form signed. The Curtin University of Technology human research ethics committee approved the study.

\section{Equipment}

Isokinetic strength was tested on the KinCom 500H dynamometer (Chattecx Corporation, Chattanooga, Tennessee, USA), and data were stored on KinCom software (version 5.3). The KinCom system has excellent reliability for speed and force $(r=0.94)$ and tension $(r=0.948) .^{30}$ Percentage body fat and mass were measured using a Bioelectrical Impedance Analysis Body Fat Monitor (TBF-521; Tanita Tokyo, Japan). This is an accurate measurement of body fat percentage when compared with dual energy $x$ ray absorptiometry $(r=0.91, \mathrm{p}=0.001){ }^{31}$

\section{Testing procedure}

After height, weight, and percentage body fat had been measured, the subject completed a standardised warm up by riding a bicycle ergometer for five minutes at a comfortable speed. The subject then stretched the lower extremity muscle groups. The limb to be tested first was randomly assigned by a coin toss. The subject was positioned prone on the plinth (fig 1).

A primary tester aligned the limb to be tested in a neutral hip position, with the axis of the KinCom lever arm aligned with the centre of the shaft of femur and the knee maintained in $90^{\circ}$ of flexion. The contralateral limb was placed in abduction of $30-40^{\circ}$ (neutral hip flexion/extension). The subject was stabilised by a seatbelt strap (figure of eight) across the sacrum and gluteal folds. Both hands were placed behind the back with face down. The knee was stabilised in a clamp to maintain the centre of rotation about the shaft of the femur and tightened to skin tightness maintaining subject comfort. A second tester placed one hand either side of the femur to keep it in a neutral position in the coronal plane. The gravity correction procedure for the lower limb and lever arm was performed..$^{32}$

The end range ER was determined by a series of movements: firstly, the limb was allowed to passively rest into hip ER; secondly, the subject actively externally rotated and, finally, the primary tester applied a gentle overpressure into ER. This was to determine a point at which no further hip ER was available. This angle was entered as the stop angle into the KinCom software and allowed the hip external rotators a full active ROM, overcoming the resistance of the internal rotators. The same method was used to determine the start angle for hip ER. Passive and active ROM measures into hip ER and internal rotation (IR) have been shown to be

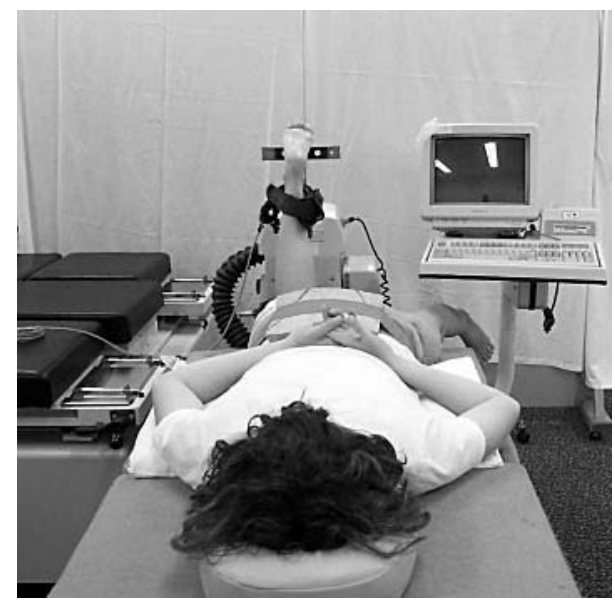

Figure 1 Strength testing position. 
Table 2 Strength and hip external rotation range of motion dependent variables

\begin{tabular}{|c|c|c|c|c|}
\hline \multirow[b]{2}{*}{ Dependent variable } & \multicolumn{2}{|l|}{ Dancers } & \multicolumn{2}{|l|}{ Non-dancers } \\
\hline & Left & Right & Left & Right \\
\hline TRAT (N.m) & $22.21(1.48)$ & $24.93(1.55)$ & $20.9(1.96)$ & $21.24(1.9)$ \\
\hline Work (J) & $28.95(2.07)$ & 37.09 (2.39) & $29.74(2.05)$ & 34.12 (2.07) \\
\hline $\mathrm{AST}_{0} \circ$ (N.m) & $30.57(2.57)^{*}$ & $33.66(2.5)^{*}$ & $23.05(2.18)$ & $25.11(2.72)$ \\
\hline $\mathrm{AST}_{20^{\circ}}$ (N.m) & $20.71(2.03)^{*}$ & $21.73(1.3)^{*}$ & $14.73(1.35)$ & $17.13(2.15)$ \\
\hline $\mathrm{AST}_{30^{\circ}}$ (N.m) & $15.33(1.74)^{*}$ & $17.36(1.25)^{*}$ & $10.29(0.83)$ & $13.15(2.04)$ \\
\hline $\mathrm{AST}_{40^{\circ}}$ (N.m) & $9.73(1.55)^{*}$ & $12.24(1.18)^{*}$ & $5.19(0.72)$ & $1.04(0.2)$ \\
\hline Inner ER ROM ( $\left.{ }^{\circ}\right)$ & $50.68(2.04)^{*}$ & $57.32(2.0)^{*}$ & $42.86(1.84)$ & $52.73(2.25)$ \\
\hline Outer ER ROM (") & $25.47(2.46)^{*}$ & $28.38(2.05)^{*}$ & $38.27(1.56)$ & $37.3(1.76)$ \\
\hline Total ER ROM (') & $76.15(2.76)$ & 85.71 (2.91) & $81.14(2.33)$ & $90.03(2.09)$ \\
\hline
\end{tabular}

reliable (all intraclass coefficient $\left.(\text { ICC })_{(3,1)}>0.95\right)^{33}$ Before strength testing was started, the subject was familiarised with the direction of movement by the KinCom performing full passive hip IR and ER.

Isokinetic strength testing proceeded, and angular velocity was set at $30 \%$ s. This followed previously used methodology $\left(\operatorname{ICC}_{(3,1)}>0.90\right) \cdot{ }^{33}$ Active external rotation was followed by active internal rotation. The first contraction in each direction was a $50 \%$ effort, followed by efforts of $75 \%$ and $90 \%$. Maximal efforts of $100 \%$ were repeated to overcome the learning effect, ${ }^{20}{ }^{34}$ until no improvements in the shape or peak of the strength curves were seen as determined by both testers. The subject was provided with verbal and visual ${ }^{35}$ feedback of the strength curves between efforts, with the aim of improving performance. A minimum 30-60 second rest period was provided between each effort to allow muscle recovery. ${ }^{6}{ }^{36}$ The best curve was recorded as determined by the regular shape and highest peak. This was saved on the KinCom software. This strength testing procedure was repeated for the opposite limb with a minimum rest period of two minutes between legs. ${ }^{6}$ At the end of testing, the subject was advised to warm down using the same protocol as for the warm up.

The hip active IR and ER ROM was determined by truncating the strength curves in each direction where angle specific force $=0 \mathrm{~N}$-that is, where $\mathrm{y}=0$. These two points represented the truncated range average force of hip ER. Data, including truncated range average force, angle specific force for ER (at $0^{\circ}, 20^{\circ}, 30^{\circ}$, and $\left.40^{\circ}\right)$, and lever arm length (m) for each subject, were entered into a Microsoft Excel (version 5.1) spreadsheet.

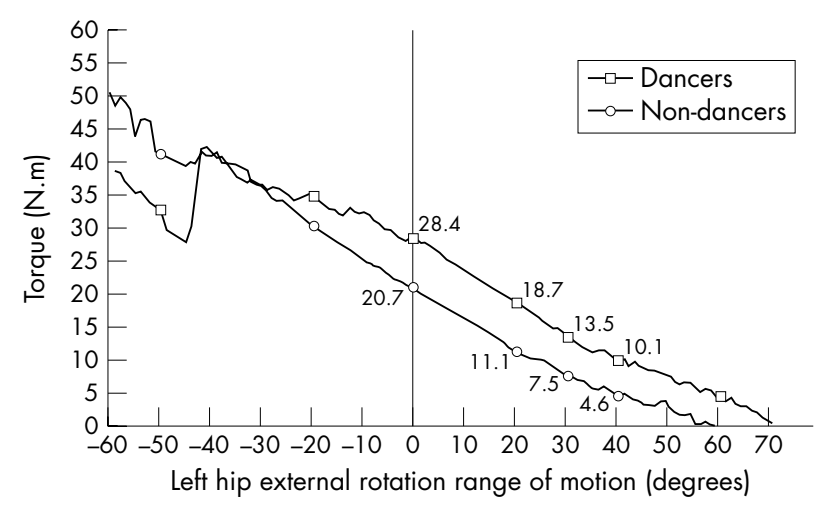

Figure 2 Strength curve for left side of dancers and non-dancers, with angle specific torque values labelled at $0^{\circ}, 20^{\circ}, 30^{\circ}$, and $40^{\circ}$.

\section{Calculations}

The following calculations were made:

- $\operatorname{LBM}=(100-(\%$ body fat $)) \times($ mass $(\mathrm{kg}))$

- $\operatorname{TRAT}(\mathrm{N} . \mathrm{m})=($ truncated range average force $(\mathrm{N})) \times$ (lever $\operatorname{arm}(\mathrm{m}))$

- $\mathrm{AST}=($ angle specific force $(\mathrm{N})) \times($ lever arm $(\mathrm{m}))$

- Work $(\mathrm{J})=(($ total active hip ER ROM $) / 180) \times \pi) \times$ TRAT

- Mean difference between sides $=(\mathrm{R}($ right $)-\mathrm{L}($ left $))$

- Mean difference between sides as a percentage $=((\mathrm{R}-$ $\mathrm{L}) / \mathrm{R} \times 100)$

In the last two calculations, a positive value indicates that the left is less (strength/ROM) than the right, and a negative value that the left is greater (strength/ROM) than the right.

\section{Statistical analysis}

Data were analysed using a computerised statistical package (SPSS version 11.5). Descriptive data were obtained for age, weight, height, LBM, and years of dance for both groups. A two way repeated measures analysis of covariance was used to compare strength data between groups. The dependent variables were: TRAT (N.m), work (J), and AST (N.m) at $0^{\circ}$, $20^{\circ}, 30^{\circ}$, and $40^{\circ}$. Dependent variables for strength comparison between groups were adjusted for LBM. A two way repeated measures analysis of variance was used to compare strength data between sides (N.m) and ROM data between groups and sides (degrees). Bonferroni correction was made for multiple analyses, and significance was accepted at $\mathrm{p} \leqslant 0.05$.

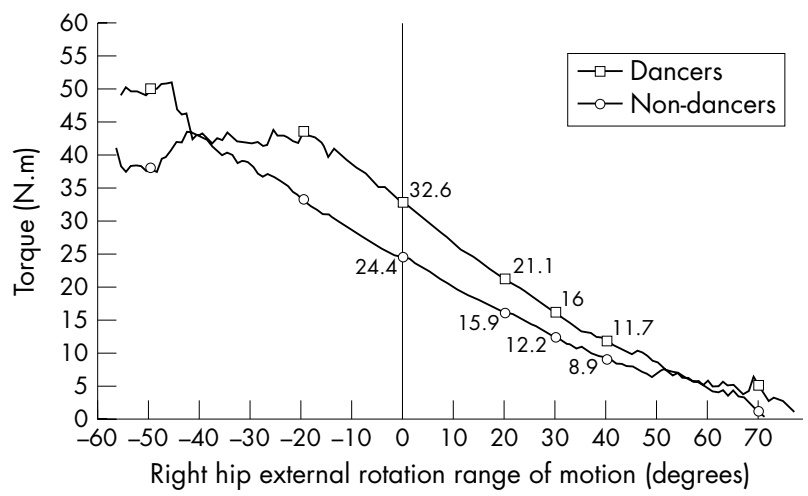

Figure 3 Strength curve for right side of dancers and non-dancers, with angle specific torque values labelled at $0^{\circ}, 20^{\circ}, 30^{\circ}$, and $40^{\circ}$. 


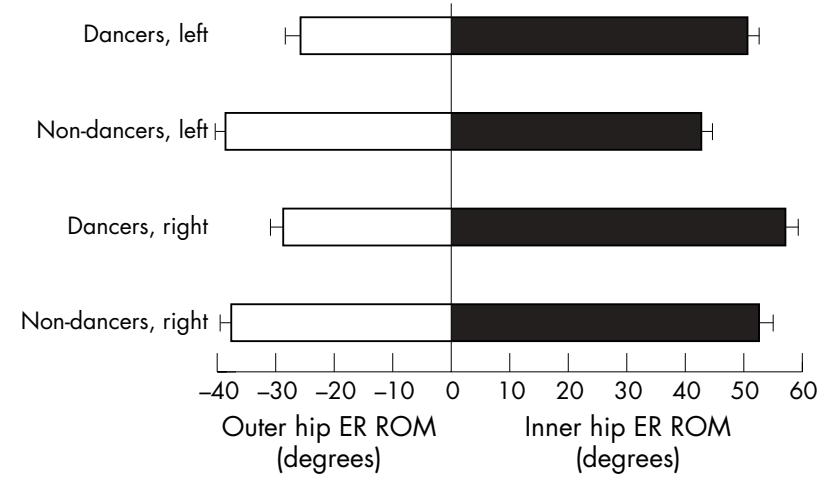

Figure 4 Hip external rotation (ER) range of motion (ROM) (mean and SEM).

\section{RESULTS}

Table 2 shows hip ER strength and ROM variables. In dancers, $\mathrm{AST}_{0}{ }^{\circ}{ }^{\mathrm{a}}, \mathrm{AST}_{20}{ }^{\circ}{ }^{\mathrm{a}}, \mathrm{AST}_{30}{ }^{\circ}$, and $\mathrm{AST}_{40}{ }^{\circ}$ a of hip ER (where superscript a means adjusted for LBM) were significantly greater than in non-dancers $\left(F_{(1,68)}=9.13\right.$, $\mathrm{p}=0.004 ; F_{(1,68)}=9.81, \mathrm{p}=0.003 ; F_{(1,63)}=5.55, \mathrm{p}=$ $0.022 ; F_{(1,45)}=33.38, \mathrm{p} \leqslant 0.001$ respectively). Hip ER strength calculated as TRAT $^{\mathrm{a}}$ and work $^{\mathrm{a}}$ were not significantly different between groups $\left(F_{(1,68)}=0.534, \mathrm{p}=0.467\right.$; $F_{(1,68)}=0, \mathrm{p}=0.989$ respectively). Figures 2 and 3 show the strength curves for left and right sides respectively in each group.

The dancers had significantly greater inner ER ROM $\left(F_{(1,69)}=6.53, \mathrm{p}=0.013\right)$, and the non-dancers had significantly greater outer ER ROM $\left(F_{(1,69)}=19.46\right.$, $\mathrm{p} \leqslant 0.001$ ) (table 3 and fig 4 ). The total ER ROM was not significantly different between the groups $\left(F_{(1,69)}=2.32\right.$, $\mathrm{p}=0.133)$. Dancers had greater hip inner ER ROM of $7.81^{\circ}$ (2.74) and $4.59^{\circ}(3.03)$ on the left and right respectively.
The right side was significantly stronger than the left side for both dancers and non-dancers for TRAT, work, $\mathrm{AST}_{0}$, $\mathrm{AST}_{20}{ }^{\circ}$, and $\mathrm{AST}_{30}{ }^{\circ}\left(F_{(1,69)}=7.75, \mathrm{p}=0.007 ; F_{(1,69)}=\right.$ $22.38, \mathrm{p} \leqslant 0.001 ; F_{(1,69)}=8.62, \mathrm{p}=0.005 ; F_{(1,69)}=8.63$, $\mathrm{p}=0.004 ; F_{(1,64)}=14.17, \mathrm{p} \leqslant 0.001$ respectively). The right side was consistently stronger at $\mathrm{AST}_{0}$, $\mathrm{AST}_{30}$, and $\mathrm{AST}_{40}{ }^{\circ}$ than the left by a greater margin in dancers than non-dancers (table 3).

The right side had a significantly greater total ER ROM and inner ER ROM than the left side $\left(F_{(1,69)}=25.33, \mathrm{p} \leqslant 0.001\right.$; $F_{(1,69)}=28.02, \mathrm{p} \leqslant 0.001$ respectively; table 4$)$.

\section{DISCUSSION}

Dancers exhibit greater angle specific hip ER strength and inner hip ER ROM than non-dancers. Although as a muscle group, the hip external rotators were not found to be stronger (TRAT or work) between groups, the dancers were able to generate significantly greater AST in the inner range of hip ER, highlighting the requirements of hip ER during turnout in ballet. This study shows the ability of the dancers to achieve significantly greater hip ER ROM (inner hip ER range) at the expense of hip IR ROM (outer hip ER range). The total hip ROM was similar between the groups (fig 4). This is supported by previous findings on hip rotation ROM in dancers. ${ }^{37-42}$ Our finding of greater inner hip ER ROM in dancers (about $8^{\circ}$ and $5^{\circ}$ on left and right respectively), although statistically significant, is unlikely to be considered clinically significant. The finding is supported by similar findings on hip rotation ROM in dancers ${ }^{43}$ and runners ${ }^{44}$ where the difference was $10^{\circ}$ or less between groups.

In our investigation, the ability of the ballet dancer to achieve extreme hip ER is demonstrated as a shift in the strength curve. There is no greater overall strength of the hip external rotators in the dancers compared with the nondancers, but they are able to achieve greater strength at angles in the inner range of hip ER (figs 2 and 3). Although it has been noted that the joint position will affect the amount of force generated by a muscle group, ${ }^{45}$ the concept of a shift

Table 3 Side to side differences in dancers and non-dancers for hip external rotation strength dependent variables

\begin{tabular}{|c|c|c|c|c|}
\hline \multirow[b]{2}{*}{ Variable } & \multicolumn{2}{|l|}{ Dancers } & \multicolumn{2}{|l|}{ Non-dancers } \\
\hline & Difference & Percentage difference & Difference & Percentage difference \\
\hline 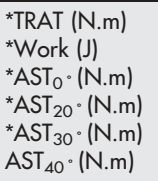 & $\begin{array}{l}3(1.09) \\
8.14(2.04) \\
3.88(1.89) \\
2.02(1.24) \\
2.74(1.14) \\
2.51(1.47)\end{array}$ & $\begin{array}{l}9.13(4.33) \\
16.04(5.86) \\
10.14(5.34) \\
10.79(7.83) \\
18(8.12) \\
0.41(21.84)\end{array}$ & $\begin{array}{l}0.99(0.93) \\
4.39(1.71) \\
2.99(1.42) \\
4.28(1.38) \\
4.3(1.5) \\
-4.15(0.75)\end{array}$ & $\begin{array}{l}1.41(4.82) \\
9.6(5.27) \\
3.86(7.04) \\
16.59(7.83) \\
2.46(16.04) \\
-663.97(159.17)\end{array}$ \\
\hline
\end{tabular}

Values are mean (SEM). The difference between the means (right - left) and percentage difference between the means ((right - left)/right $\times 100)$ are shown. Negative values indicate that left is greater than the right.

*Right significantly greater than left $(p \leqslant 0.05)$.

TRAT, Truncated range average torque; AST, angle specific torque; ER, external rotation; ROM, range of motion.

Table 4 Side to side differences in dancers and non-dancers for hip external rotation (ER) range of motion dependent variables

\begin{tabular}{|c|c|c|c|c|}
\hline \multirow[b]{2}{*}{ Variable } & \multicolumn{2}{|l|}{ Dancers } & \multicolumn{2}{|l|}{ Non-dancers } \\
\hline & Difference & Percentage difference & Difference & Percentage difference \\
\hline $\begin{array}{l}\text { *Inner ER }\left(\left(^{\circ}\right)\right. \\
\text { Outer ER ( } \\
\text { *Total ER }\left(1^{\circ}\right)\end{array}$ & $\begin{array}{l}6.65(1.78) \\
2.91(2.08) \\
9.56(2.74)\end{array}$ & $\begin{array}{l}10.51(3) \\
1.29(13.66) \\
9.43(3.22)\end{array}$ & $\begin{array}{l}9.86(2.5) \\
-0.97(1.57) \\
8.89(2.45)\end{array}$ & $\begin{array}{l}13.16(5.74) \\
-8.81(5.79) \\
8.95(2.71)\end{array}$ \\
\hline
\end{tabular}

Values are mean (SEM). The difference between the means (right - left) and percentage difference between the means ((right - left)/right $\times 100)$ are shown. Negative values indicate that left is greater than the right.

*Right significantly greater than the left $(p \leqslant 0.05)$. 
in this curve has not been demonstrated when groups such as dancers and non-dancers have been compared. This shift is significant as it may show a training effect related to angle specific strength.

The observed differences in AST and hip ER ROM may be due to adaptive, physiological changes. These changes may represent a shortening of the hip external rotators and posterior hip joint capsule, with a concomitant lengthening of hip internal rotators and anterior capsule. ${ }^{39-41} 46$ Adaptive changes to the active, passive, and neural subsystems ${ }^{47-49}$ in response to the functional demands of ballet training may be involved. These changes suggest a shift in the strength curve from the anatomical neutral position towards the inner range of hip ER, while the total hip ER ROM remains unchanged. Physiological reasons for greater hip ER ROM in dancers that have so far been discounted are femoral anteversion ${ }^{50}$ and joint hypermobility, ${ }^{51}$ neither of which are more prevalent in dancers.

Apart from the characteristics of joint angle, velocity, and muscle action being affected by training, compensatory strategies in the kinetic chain may occur as a result of dancers consistently aiming to achieve extreme hip ER. A compensatory strategy noted to occur is an increase in the dancer's lumbar lordosis as a result of attempting to increase hip ER. ${ }^{10}$ This altered biomechanical position is not only seen to increase the available hip ER ROM, ${ }^{5}$ it may also change the position of the centroid of rotation of the hip and alter the line of pull of the external rotators to allow a change in ER force production. It is acknowledged that the kinetics of the hip, pelvis, and lumbar spine are linked..$^{52-55}$ However, the synergistic movement at the pelvis and lumbar spine in relation to triplanar movement at the hip has not been investigated in dancers to confirm the relation of increased hip ER to lumbar lordosis. ${ }^{56}$ This altered hip position may result in the dancers not being in a "true" neutral position relative to non-dancers when lying prone. Hence, the comparison of strength results between dancers and nondancers is a comparison of functional lumbar neutral positions.

Ballet is inherently a bilateral activity. ${ }^{3}$ It is assumed that athletes participating in activities that demand symmetrical motor tasks have similar strength in the two lower extremities. ${ }^{57}$ However, the right hip external rotators of dancers and non-dancers have significantly greater strength (TRAT, work, $\mathrm{AST}_{0}{ }^{\circ}$ and $\mathrm{AST}_{30}{ }^{\circ}$ ) than the left, and this asymmetry is more pronounced in dancers. This greater asymmetry may result from dancers favouring one side when training or performing because of limb preference. ${ }^{58} 59$

Clinically, the predilection for one side in dance specific poses and postures during training may lead to individual side to side differences. This may result in alterations in biomechanics and transference of force in the kinetic chain, muscle imbalances, and deleterious change to the active, passive, and neural ${ }^{60}$ subsystems, which may be associated with injury. ${ }^{16}{ }^{17}$ The greater difference between the sides in dancers than non-dancers in this investigation may lead to such kinematic changes and be a risk factor for injury.

A feature of this investigation is the use of isokinetic testing, which is the method of choice for demonstrating a shift in the length-tension curve, ${ }^{61}$ with respect to nondancers. Furthermore, testing at a low velocity $(30 \%)$ is reported to have advantages over faster testing speeds. More deficits in muscular function are revealed, as the lower speed allows the subject to generate a higher maximal force. ${ }^{57}$ Low speeds more closely replicate the role of the hip external rotators, as they maintain the hip in ER rather than act in high speed movements like the quadriceps and hip extensors in jumping or landing. Testing in a hip neutral position more closely replicates the upright position of the dancer, ${ }^{24}$
What is already known on this topic

Ballet dancers have greater strength at angles of inner range hip external rotation range than non-dancers. This may be an adaptive response to the requirement of extreme hip external rotation.

maintaining the role of the external rotators to create ER rather than IR, which occurs when the hip is flexed to $90^{\circ}$ as in other testing positions. ${ }^{24}{ }^{62}{ }^{63}$ Measuring force through the full available active hip ER ROM for each subject, rather than using arbitrary limits to hip rotation ROM for all subjects, allowed analysis of the full strength curve. Finally, providing visual $^{193}$ and verbal feedback encouraged subjects to maximal effort.

The heterogeneity of the dance subjects is a limitation of this investigation, as they were from both ballet and contemporary styles of dance. Testers were not blinded to the group allocation, leading to possible systematic error, whereby visual and verbal feedback and interpretation of the graphs may not have been equal between all subjects tested. A further limitation was the difficulty of controlling the time and day of testing. This may have affected the LBM measurements. Strength testing about the hip inherently has the problem of adequate thigh stabilisation to avoid compensatory strategies that may affect the strength curves. Finally, force generated about the hip joint may not represent the actual strength produced, as the axis of rotation used is the shaft of femur, not the true axis of rotation about the hip joint.

Clinical findings of this study are:

- Dancers show greater hip ER strength into extremes of hip ER.

- Greater hip ER ROM is not the sole prerequisite of a dancer, rather strength and ROM at angles specific to the demands of ballet are required.

- Dancers exhibit a greater right to left side strength difference than non-dancers and this greater asymmetry must be kept in mind when assessing a dancer's strength as it shows their preference of a single limb. This asymmetry may contribute to alterations in the kinetic chain and may be a risk factor for injury.

- Musculoskeletal assessment or screening of dancers must include strength measurements at angles specific to the demands of the task, rather than assume overall strength differences to exist between trained and untrained populations for specific muscle groups.

Suggestions for future research are investigation of the strength changes that may occur prospectively, establishment of normal side to side differences as a baseline for comparison with other dance and athletic populations, and development of dance screening protocols to include accurate angle specific strength and ROM testing protocols.

\section{ACKNOWLEDGEMENTS}

We acknowledge the expert advice of Mr Geoff Strauss in isokinetic testing procedures on the KinCom dynamometer and Dr Kathy Briffa for her assistance with statistical analysis.

\section{Authors' affiliations}

A Gupta, B Fernihough, G Bailey, P Bombeck, D Hopper, School of

Physiotherapy, Curtin University, Bentley, WA 6102, Australia

A Clarke, Curtin University, Bentley, WA 6102, Australia

Conflict of interest: none declared 


\section{REFERENCES}

1 Grant G. In: Technical manual and dictionary of classical ballet, 3rd ed. New York: Dover Publications, 1982

2 Bowling A. Injuries to dancers: prevalence, treatment and perception of causes. BMJ 1989;298:731-4.

3 Gelabert R. Dancers' spinal syndromes. J Orthop Sports Phys Ther 1986:7:180-91.

4 Gilbert CB, Gross MT, Klug KB. Relationship between hip external rotation and turnout angle for five classical ballet positions. J Orthop Sports Phys Ther 1998;27:339-47.

5 Khan K, Brown J, Way S, et al. Overuse injuries in classical ballet. Sports Med 1995: 19:341-57.

6 Kushner S, Saboe L, Reid D, et al. Relationship of turnout to hip abduction in professional dancers. Am J Sports Med 1990; 18:286-96.

7 Watkins A, Woodhull-McNeal AP, Clarkson PM, et al. Lower extremity alignment and injury in young, preprofessional, college, and professional ballet dancers. Med Probl Perform Art 1989:148-53.

8 Kapandii IA. The physiology of the joints, 1 st ed. London: Churchill Livingstone, Longman Group Limited, 1970.

9 Kushner S, Reid D, Saboe L, et al. Isokinetic torque values of the hip in professional ballet dancers. Clin J Sport Med 1992;2:114-20.

10 Micheli IJ. Back injuries in dancers. Clin Sports Med 1983;2:473-84.

11 Poggini L, Losasso S, lannone S. Injuries during the dancers growth spurt: etiology, prevention and treatment. Journal of Dance Medicine and Science 1999:3:73-9.

12 Schon LC, Weinfeld SB. Lower extremity musculoskeletal problems in dance. Curr Opin Rheumatol 1996;8:130-42.

13 Byhring S, Bo K. Musculoskeletal injuries in the Norweigan National Ballet: a prospective cohort study. Scand J Med Sci Sports 2002;12:365-70.

14 Reid DC. Preventing injuries to the young ballet dancer. Physiotherapy Canada 1987;39:231-5.

15 Rovere GD, Webb L, Gristina AG, et al. Musculoskeletal injuries in theatrical dance students. Am J Sports Med 1983;11:195-9.

16 Knapik JJ, Bauman CL, Jones BH, et al. Preseason strength and flexibility imbalances associated with athletic injuries in female collegiate athletes. Am J Sports Med 1991;19:76-81.

17 Nadler SF, Malanga GA, DePrince $M$, et al. The relationship between lower extremity injury, low back pain, and hip muscle strength in male and female collegiate athletes. Clin J Sports Med 2000;10:89-97.

18 Behm DG, Sale DG. Velocity specificity of resistance training. Sports Med 1993;15:374-88

19 DiNubile NA. Strength training. Clin Sports Med 1991;10:33-62.

20 McArdle WD, Katch Fl, Katch VL. In: Exercise physiology: energy, nutrition and human performance, 5th ed. Philadelphia: Lippincott, Williams and Wilkins, 2001.

21 Kirkendall DT, Bergfeld JA, Calabrese L, et al. Isokinetic characteristics of ballet dancers and the response to a season of ballet training. J Orthop Sports Phys Ther 1984;5:207-11.

22 Bennell K, Khan KM, Matthews B, et al. Changes in hip and ankle range of motion and hip muscle strength in 8-11 year old novice female ballet dancers and controls: a twelve month follow up study. Br J Sports Med 2001;35:54-9.

23 Hunt GC, Fromherz WA, Danoof J, et al. Femoral transverse torque: an assessment method. J Orthop Sports Phys Ther 1986;7:319-24.

24 Lindsay DM, Maitland ME, Lowe RC, et al. Comparison of isokinetic internal and external hip rotation torques using different testing positions. J Orthop Sports Phys Ther 1992;16:43-50.

25 Calahan TD, Johnston ME, Liu S, et al. Quantitative measurements of hip strength in different age groups. Clin Orthop 1989;246:136-45.

26 Benson JE, Geiger CJ, Eiserman PA, et al. Relationship between nutrient intake, body mass index, menstrual function, and ballet injury. J Am Diet Assoc 1989;89:58-63.

27 Jaric S. Muscle strength testing. Use of normalisation for body size. Sports Med 2002;32:615-31.

28 Berlet GC, Kiebzak GM, Dandar A, et al. Prospective analysis of body composition and SF36 profiles in professional dancers over a 7-month season. Is there a correlation to injury? Journal of Dance Medicine and Science 2002;6:54-61.

29 Nadler SF, Malanga GA, Feinberg JH, et al. Relationship between hip muscle imbalance and occurrence of low back pain in collegiate athletes: a prospective study. Am J Phys Med Rehabil 2001;80:572-7.

30 Farrell M, Richards JG. Analysis of the reliability and validity fof the kinetic communicator exercise device. Med Sci Sports Exerc 1986;18:44-9.

31 Austin MA, Heymsfield SB, Nieman DC. Body composition measurement in females with leg-to-leg bioelectrical impedance analysis compared to DEXA. Arlington Heights, IL: Tanita Corporation of America, 2003.

32 Finucane SD, Mayhew TP, Rothstein JM. Evaluation of the gravity-correction feature of a Kin-Com isokinetic dynamometer. Phys Ther 1994;74:1125-33.
33 Pesich G, Hunter J, Bowman S. Femoral ante-version, hip rotation range and strength in athletes with and without groin pain [abstract]. Sports Physiotherapy for Lower Limb Injuries: Clinical Expertise and Scientific Evidence, 21-23 February, 2003, Marriott Resort, Surfers Paradise, Queensland, Australia, St Kilda Central: Australian Physiotherapy Association, Sports Physiotherapy Australia, 2003:44.

34 McComas AJ. Human neuromuscular adaptations that accompany changes in activity. Med Sci Sports Exerc 1994;26: 1498-509.

35 Hopper DM, Anders M, Andersen H, et al. The influence of visual feedback on power during leg press on elite field hockey players. Physical Therapy in Sport 2004;in press.

36 Parcell AC, Sawyer RD, Tricoli VA, et al. Minimum rest period for strength recovery during a common isokinetic testing protocol. Med Sci Sports Exerc 2002;34:1018-22.

37 Bennell K, Khan KM, Matthews B, et al. Hip and ankle range of motion and hip muscle strength in young novice female ballet dancers and controls. Br J Sports Med 1999;33:340-6.

38 DiTullio M, Wilczek L, Paulus D, et al. Comparison of hip rotation in female classical ballet cancers versus female nondancers. Med Probl Perform Art 1989:4:154-8.

39 Hamilton WG, Hamilton LH, Marshall P, et al. A profile of the musculoskeletal characteristics of elite professional ballet dancers. Am J Sports Med 1992:20:267-73.

40 Khan K, Roberts P, Nattrass C, et al. Hip and ankle range of motion in elite classical ballet dancers and controls. Clin I Sport Med 1997;7:174-9.

41 Micheli L, Gillespie WJ, Walaszek A. Physiologic profile of female professional ballerinas. Clin Sports Med 1984;3:199-209.

42 Reid DC, Burnham RS, Saboe LA, et al. Lower extremity flexibility patterns in classical ballet dancers and their correlation to lateral hip and knee injuries. Am J Sports Med 1987; 15:347-52.

43 Khan KM, Bennell K, Ng S, et al. Can 16-18 year-old elite ballet dancers improve their hip and ankle range of motion over a 12 -month period? Clin J Sport Med 2000;10:98-103.

44 Hoolman JH, Burgess B, Bokermann JC. Passive hip rotation range of motion: effects of testing position and age in runners and non-runners. Physiotherapy Theory and Practice 2003;19:77-86.

45 Amundsen LR. Isometric muscle strength testing with fixed load cells. In: Amundsen LR, ed. Muscle strength testing:instrumented and non-instrumented systems. 1st ed. New York: Churchill Livingstone, 1990:89-121.

46 Sammarco GJ. The dancer's hip. Clin Sports Med 1983;2:485-99.

47 Judge LW, Moreau C, Burke JR. Neural adaptations with sports-specific resistance training in highly skilled athletes. J Sports Sci 2003;21:419-27.

48 Moritani T. Neuromuscular adaptations during the acquisition of muscle strength, power and motor tasks. J Biomech 1993;26(suppl 1):95-107.

49 Panjabi M. The stabilizing system of the spine. Part 1 and Part 2. J Spinal Disord 1992:5:383-97.

50 Bauman PA, Singson R, Hamilton WG. Femoral neck anteversion in ballerinas. Clin Orthop 1994;302:57-63.

51 Klemp P, Learmonth ID. Hypermobility and injuries in a professional ballet company. Br J Sports Med 1984:18:143-8.

52 Lee D, Vleeming A. The pelvic girdle: an approach to the examination and treatment of the lumbo-pelvic-hip region, 2nd ed. Edinburgh: ChurchillLivingstone, 1999

53 Lee RYW, Wong TKT. Relationship between the movements of lumbar spine and hip. Human movement science 2002;21:481-94.

54 Penning L. Psoas muscle and lumbar spine stability: a concept uniting existing controversies. Critical review and hypothesis. Eur Spine J 2000;9:577-85.

55 Tully EA, Wagh P, Galea MP. Lumbofemoral rhythm during hip flexion in young adults and children. Spine 2002;27:E432-40.

56 Fitt SS. Dance kinesiology, 2nd ed. New York: Wadsworth Publishing, 1996.

57 Sapega AA. Current concepts review: muscle performance evaluation in orthopaedic practice. J Bone Joint Surg [Am] 1990;72:1562-74.

58 Beling J, Wolfe GA, Allen KA, et al. Lower extremity preference during gross and fine motor skills performed in sitting and standing postures. J Orthop Sports Phys Ther 1998;28:400-4.

59 Murphy DF, Connolly DAJ, Beynnon BD. Risk factors for lower extremity injury: a review of the literature. Br J Sports Med 2003;37:13-59.

60 Mikheev M, Mohr C, Afanasiev S, et al. Motor control and cerebral hemispheric specialisation in highly qualified judo wrestlers. Neuropsychologia 2002;40:1209-19.

61 Wilk K. Dynamic muscle strength. In: Amundsen LR, ed. Muscle strength testing. Instrumented and non-instrumented systems. Melbourne: Churchill Livingstone, 1990:123-50.

62 Delp SL, Maloney W. Effects of hip center location on the moment-generating capacity of the muscles. J Biomech 1993;26:485-99.

63 Delp SL, Hess WE, Hungerford DS, et al. Variation of rotation moment arms with hip flexion. J Biomech 1999:32:493-501. 